\title{
Dual-band UWB antenna for Surface Movement
}

\author{
Radar \\ S. Aourik ${ }^{1}$, A. Errkik ${ }^{1}$, L. Elabdelaoui ${ }^{1}$, A. Tajamouati ${ }^{1}$, M. $^{2}$ Latrach $^{2}$
}

1 LMEET, FST of Settat, Hassan 1st University, Settat, Morocco

2 Microwave group, ESEO, Anges, France

\begin{abstract}
The proposed antenna radiation size is $9.4 \times 6.12 \mathrm{~mm}$ with low permittivity value 2.22 , loss tangent value 0.0004 and $0.4 \mathrm{~mm}$ thickness Duroid 5880 dielectric substrate material were used. An inset microstripline feed has been used because of its simplicity and ease of practical manufacturing. The parametric study is performed with a change of the form of patch to achieve the Ka- band UWB frequency, dual-band and a high gain. The Proposed antenna impedance bandwidth (VSWR $<2)$ is achieved with wide band characteristics $1 \mathrm{GHz}(23.3-24.3 \mathrm{GHz})$ on the lower Ka- band frequency and $2 \mathrm{GHz}(27.4-29.4 \mathrm{GHz})$ on the upper Ka-band frequency. An extensive analysis of the return loss, gain and efficiency of the proposed antenna is discussed in this paper. The antenna is simulated by computer software technology Microwave studio (CST), the presented antenna competent for the satellite and radar applications in Ka-band.
\end{abstract}

Keywords: microstrip patch antenna, Ka-band, surface movement radar (SMR), UWB, dual-band.

\section{Introduction}

Aircraft traffic ground movement has a big impact on airports capacity also on the congestion in surrounding airspace. It has a great influence on the safety and quality services as well as the economy of air transport operations. The conditions of reduced visibility can cause disturbances in the terminal area of the airport, causing significant delays for both flight and ground movement aircraft.

In order to increase airport capacity and enhance the level of safety during reduced visibility operations The International Civil Aviation Organization (ICAO: United Nations Specialized Agency for the Establishment of the Global Regulatory Framework for the Safety of International Civil Aviation) has developed advanced surface motion guidance and control systems (A-SMGCS) through the use of modern technologies and a high degree of integration of the various functions (Manual A-SMGCS 9830) [1].

Following the same goal, the European organization of the air navigation safety EUROCONTROL, as part of its project to improve air traffic flows and capacity management ( ATFCM ) at airports by minimising delays, and by optimising the use of resources, has published specifications for the implementation of the essential requirements to the system A-SMGCS which manifests the requirement for a non-cooperative sensor in the surveillance part of airport to visualise the position of the aircraft on the aerodrome(Version 1.0 - 1 March 2018 ) [2].

Surface Movement Radar (SMR) plays a vital role in the overall safety management system of airports. It provides all the necessary information to establish safe and efficient flight paths for aircrafts even under high complexity conditions. (Reduced visibility, night operations).

Accurate and reliable sensors are necessary to provide detailed information to air traffic controllers and crew amount. The radar antenna or the sensor is the key word in the radar system, having a high performance antenna in terms of resolution allows the accurate and reliable detection of all projects on the movement area. Very short transmission pulses of a few nanoseconds allow a high range resolution, which permits visualisation of aircraft contours on the radar display. In the rapid development of wireless communication, a compact and discrete antenna is essential which presents a high quality price ratio, reasonable mass and size of the system. [3] [4]In the literature several studies have been presented to have a dependent radar antenna on the requirements that 
imply a migration towards the band Ka following the high performance of directivity compared to the band already used.

\section{Radar equation [5]}

The radar equation reflects the influence of physical phenomena on the radiated power, from to the propagation of the wave until the reception of the reflected signal (echo), allows the performance estimate of the radar system. The total power captured by the radar which depends on the equivalent surface Ae of the radar antenna is:

$$
\operatorname{Pr}=\frac{P t \times G^{2} \times \lambda^{2} \times \sigma}{(4 \pi)^{3} \times R^{4} \times(L p)}
$$

$P t, G, \sigma, \lambda, R$ et and $L p$ are respectively the power of radiation, the gain in power, the cross-section (or the radar-SER-equivalent surface), the wavelength of the radiation, the distance between the radar and the target and $L p$ is the loss factor due to atmospheric losses, losses of the transmission and reception chains.

This expression shows that the intensity of the echo signal is proportional to the radiation power, to the square of the gain, to the effective cross section (span) of the aircraft and to the square of the wavelength, so the maximum range of the radar depends on the square root of the Gain. This results in the performance of the antenna which has a very great influence on the performance of the radar. On the other hand the resolution of surveillance radar is divided into two parts: the distance resolution and the angular resolution (in azimuth):

$\checkmark$ The distance resolution $\Delta \mathrm{R}$ is the ability of a radar system to distinguish two or more targets in the same direction but at different distances. The quality of the resolution depends on the bandwidth $\Delta \mathrm{f}$ of the transmitted pulse.

$$
\Delta R=\frac{c}{2 \Delta f} \text { With }\left({ }_{\Delta f}=\frac{\int_{-\infty}^{+\infty}|S(f)|^{2}}{\left|S(f)^{2}\right|} d f \text { and } \mathrm{S}(\mathrm{f}) \text { signal spectrum } \mathrm{s}(\mathrm{t})\right)
$$

In the case of an unmodulated pulse, $\Delta R=\frac{c}{2 \Delta f}$ the distance resolution is increased by a radar antenna with a broadband based on the transmission of very short pulses, often less than the nanosecond we speak here about margin of gigahertz.

$\checkmark$ Angular resolution is the minimum angular difference that allows the radar to distinguish two identical targets at the same distance. The angular resolution of a radar is determined by the width of its antenna lobe, itself defined by its angle at $-3 \mathrm{~dB}$ (half-power lobe width), more the lobe is narrower, more the directivity of the antenna is important.

Current wireless communication systems and radar systems require higher speed transmission to support various services. A UWB system with high directivity and gain is considered as a promising solution to the problem of distance and angular resolution.

Various radar systems such as Synthetic Aperture Radar (SAR), Shuttle Imaging Radar, Remote Sensing Radar and other wireless communication systems operate in the L, C and X bands [6][7]. The higher the frequency is, the greater the atmospheric absorption is, and causes the attenuation of the radar beam which limits the distance resolution and range. Ka-band radars are known by their very short range, their extremely high precision and their highly fast rate of scanning, they use very short pulses of a few nanoseconds at these frequencies, they can also follow the movements of the vehicles on the tarmac and the airport runways, their resolution permits the visualization of the vehicles silhouette [4].

The micro-band antenna is the first option for this high-frequency band because of its low cost, light weight and robustness. Many researchers have worked and presented studies on micro-band antennas (Patch) which make it possible to obtain the expected solution [8]-[10]. With a narrower beam and lower output power than the $\mathrm{X}$ and $\mathrm{K}$ bands, the Ka-band antennas are the most persuasive radar type in the various research and recommendations, with a challenge of getting a wide duel band and increase Gain with a radiation pattern characterized by a narrow main lobe and eliminated the side lobes for a frequency band between 26.5 and 40 GHz. 


\section{Proposed antenna}

The study was deeply made in order to design an antenna for surface movement Radar application; the two resonant frequencies wait respectively the reception and emission in a margin of [23-28] GHz. Many researchers have worked and presented the techniques to get multiband operation using multi stack patches [11].

Using U-slot loaded patch stacked with H-shaped parasitic elements [12]. In [13] an annular ring patch is loaded with a slot, where the loaded slot makes the design capable for dual band operation. Two asymmetric horizontal strips are used as additional resonator to produce the lower and upper resonant modes [14]. Although U-slot patch antenna is used is concerned with broadband capabilities and U slot to obtain triple band with a second slot is needed [15]. Multi frequency operation can also be achieved using spiral printed antennas, Bowtie patches loaded with slots, multiple patches, cutting rectangular patch with L-shaped slit, U-slot and inserting slits with different dimensions and adjust the length, width according to the resonance frequency and also different feeding techniques applied to match the impedance [16], [17].

\section{- Structure and Scope of the antenna}

The geometry of the proposed antenna is based on a rectangular patch stacked by two U-Slots used asymmetrically, to improve the antenna operation, an H-shaped slot has been stacked for the purpose of having an optimal surface current distribution, the length and width of the slots will be adjusted according to the resonant frequency to receive the High gain possible and voltage standing wave ratio (VSWR) less than 2 and to get stable radiation characteristics throughout the frequency band $23.3 \mathrm{GHz}$ to $29.3 \mathrm{GHz}$. . The feeding technique used is the microstrip line supported by notches in order to have a good adaptation of input impedance; a L-slot was loaded in microstrip line feed to produce multi-band operation lower and higher resonance modes.

Among the different substrates used is the FR-4 substrate which is widely used in patch antennas. The inconvenience of FR-4 is that it is difficult for a higher bandwidth; therefore the dielectric constant of the antenna substrate should be as low as possible to increase the impedance bandwidth and reduce the wave excitation surface. The use of a low dielectric constant substrate increases also the bandwidth because it is inversely proportional to the dielectric constant. The proposed antenna is printed on a Duroid 5880 substrate material which has a reduced value of the constant dielectric with relative permittivity $=2.22$ and loss tangent of 0.0004 , operating up to $40 \mathrm{GHz}$ with good thermo-mechanical stability. Table.1 Duroid 5880 has lowest dielectric constant among the different substrates which also increases the bandwidth because bandwidth is inversely proportional to dielectric constant.

Table 1. DIELECTRIC PROPERTIES OF DIFFERENT SUBSTRATE MATERIALS

\begin{tabular}{|c|c|c|}
\hline Material & Permittivity & Loss tangent \\
\hline Duroid 5880 & 2.22 & 0.0004 \\
\hline Duroid 5870 & 2.33 & 0.0023 \\
\hline Duroid 6010 & 10.8 & 0.0023 \\
\hline FR4 & 4.66 & 0.020 \\
\hline
\end{tabular}

In the design of a rectangular micro ribbon patch, two parameters are important (the length and width of the patch). These two parameters depend on the resonance frequency, the dielectric constant of the substrate used and its thickness. They are calculated as follow [18]:

\subsection{The width of the patch:}

The width $\mathrm{W}$ is calculated from the formula of Bahl and Bhartia:

$$
W=\frac{c}{2 f_{r}}\left(\frac{\varepsilon_{r+1}}{2}\right)^{-0.5}
$$

\subsection{Edge effect (Fringing Effect) :}

The propagation is done in two different dielectric environments: the relative permittivity air equal to 1 and the relative permittivity substrate $\varepsilon r$ with two different speeds, taking into account this inhomogeneity, an effective medium of permittivity $\varepsilon r e f f$ replaces the two previous environments.

For $\mathrm{W} / \mathrm{h}>1 ; \quad$ ereff is given by the explicit formula of Hammerstad: 


$$
\varepsilon_{\text {reff }}=\frac{\varepsilon_{r}+1}{2}+\frac{\varepsilon_{r}-1}{2}\left[1+12 \frac{h}{W}\right]^{-0.5}
$$

$\varepsilon_{\text {reff }}:$ Effective Permittivity. $\varepsilon_{r}$ : Relative permittivity. $h:$ Substrate height

\subsection{The effective length}

Due to the effect of the edge, electrical dimensions appear which are longer than the physical dimensions. For the rectangular patch the length $\mathrm{L}$ is extended by two $\Delta L$. This extension is given by the empirical formula of Hammerstad:

$$
\Delta L=0.412 h \frac{\left(\varepsilon_{r e f f}+0.3\right)}{\left(\varepsilon_{\text {reff }}-0.258\right)} \frac{\left(\frac{W}{h}+0.264\right)}{\left(\frac{W}{h}+0.8\right)}
$$

- The effective length Leff of the patch becomes:

$$
L_{e f f}=L+2 \Delta L
$$

- For a given frequency $f r$ the effective length is given by:

$$
L_{e f f}=\frac{c}{2 f_{r} \sqrt{\varepsilon_{\text {refff }}}}=\frac{\lambda_{g}}{2}
$$

, Where $\lambda g$ is the guided wavelength in effective medium.

According to the design calculation above, the proposed antenna was designed with $9.4 \times 6.12 \mathrm{~mm}$ dimensions, is powered by micro strip line feeding techniques. The geometry of the proposed antenna is illustrated in the following Figure 1:

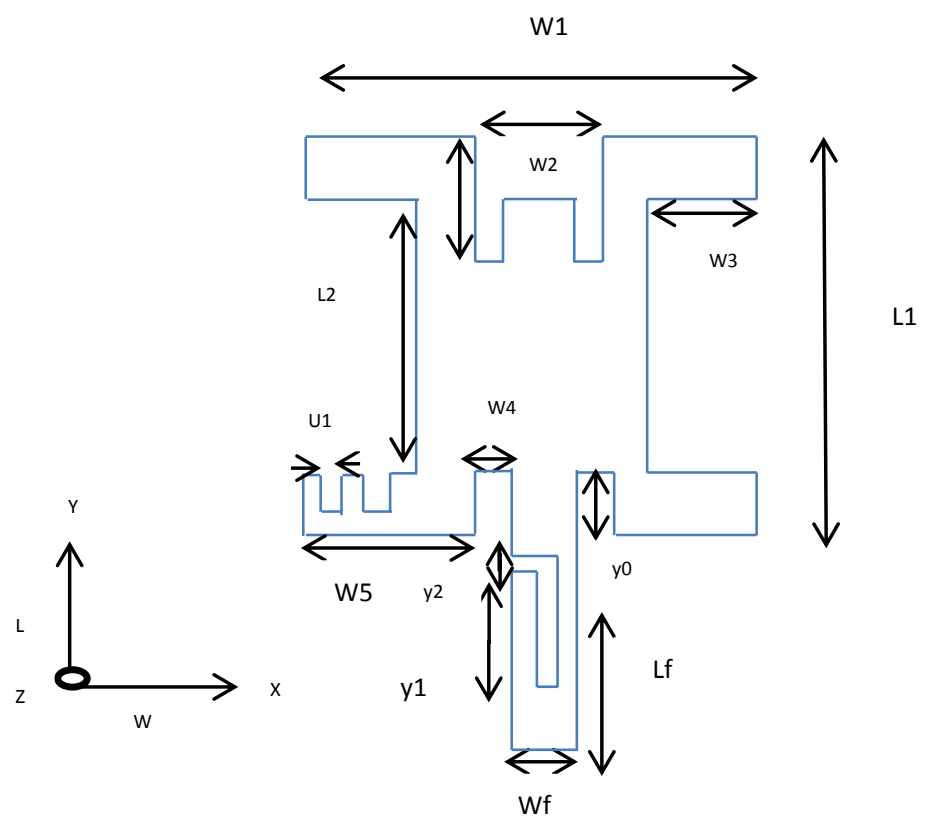

Fig.1. Geometry of the proposed antenna.

The radiating dimensions of proposed antenna are follows:

$\mathrm{W} 1=9.4 \mathrm{~mm}, \mathrm{~L} 1=6.12 \mathrm{~mm}, \mathrm{~W} 2=1.45 \mathrm{~mm}, \mathrm{~W} 3=2.8 \mathrm{~mm}, \mathrm{~W} 4=0.2 \mathrm{~mm}, \mathrm{~W} 5=4.22 \mathrm{~mm}, \mathrm{~L} 2=5.12 \mathrm{~mm}, \mathrm{Lf}=3.9$ $\mathrm{mm}, \mathrm{y} 0=1.2 \mathrm{~mm}, \mathrm{Wf}=0.4 \mathrm{~mm}, \mathrm{y} 1=2.2 \mathrm{~mm}, \mathrm{y} 2=0.5 \mathrm{~mm}, \mathrm{u} 1=0.5 \mathrm{~mm}, \mathrm{u} 2=0.25 \mathrm{~mm}, \mathrm{y} 4=1.92 \mathrm{~mm}$. 


\section{RESULTS AND DISCUSSIONS}

The antenna performances were analyzed with the Computer Simulation Technology (CST), the geometry of the proposed antenna in shown in Figure 2. It is printed on Duroid 5880 substrate material with low permittivity of 2.22 and thickness of $0.4 \mathrm{~mm}$, the ground size of proposed antenna is $18.5 \times 3.9 \mathrm{~mm}$ which is shown in Figure 2,3.

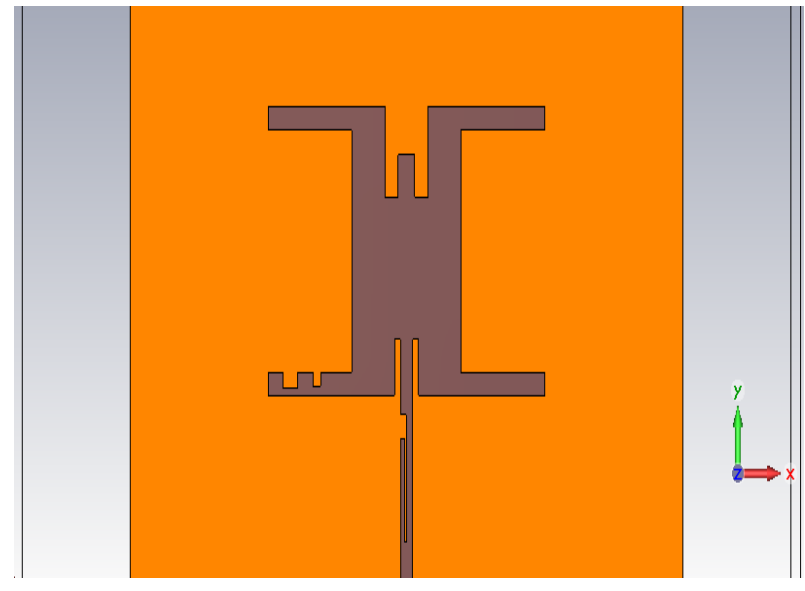

Fig.2. Design front of the proposed antenna.

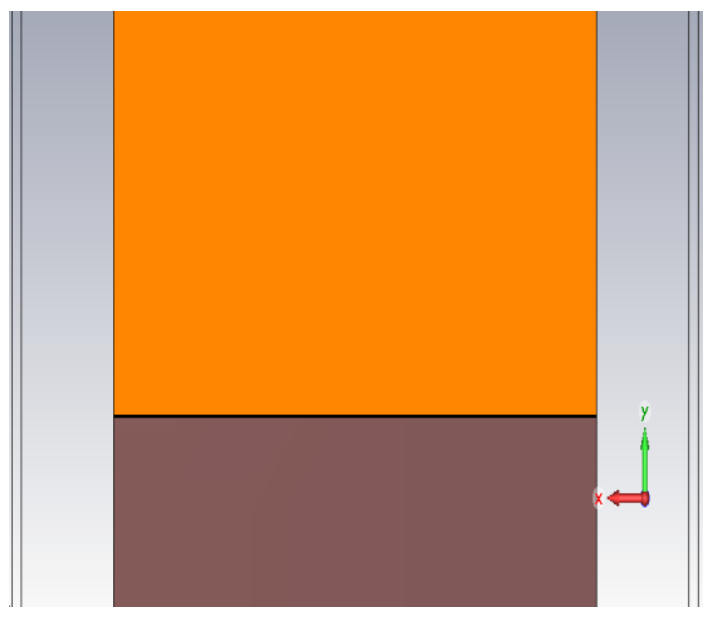

Fig.3. Back side of the proposed antenna

The proposed antenna has as a base a rectangular patch structure with dimensions calculated by transmission line model equations, in order to have a UWB in the margin of the band $\mathrm{Ka}$, , the result of the design is presented in Figure 2.

The proposed antenna was developed by the following steps:

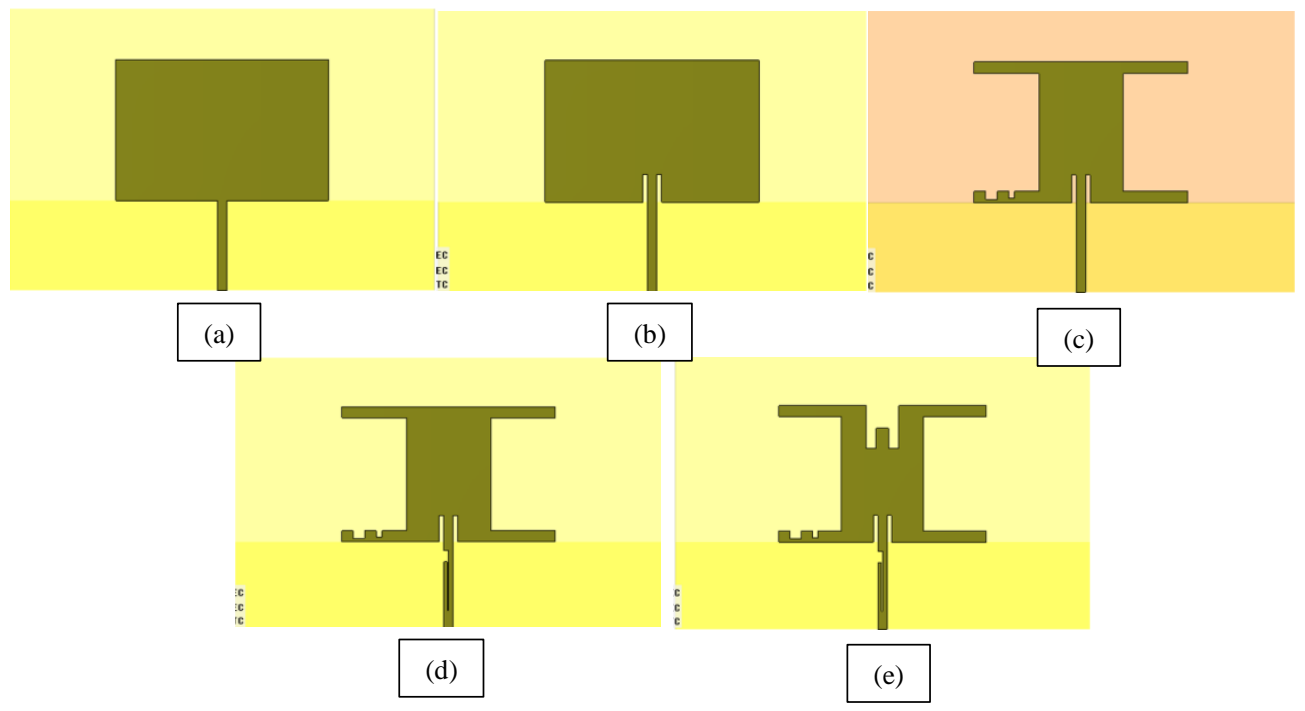

Fig.4. steps followed to optimize the proposed antenna.

(a) the proposed antenna is a basic structure of a rectangular patch antenna powered by a microstrip line, its dimensions are calculated by the transmission line analysis method to obtain resonance on the Ka frequency range. The patch etched on a substrate characterized by permittivity $=2.22$ and tangent loss of 0.0004 . The partial ground plane under the feeding part plays a vital role in increasing the bandwidth. This is due to the electromagnetic coupling between the split ground plane and the radiating patch. (b) in this work, we have chosen to excite the antenna with a feed line with notch because it is easy to manufacture, and simple to adapt to the antenna. The impedance of the patch is given by the relation [19] $Z_{a}=90 \frac{\varepsilon_{r}^{2}}{\varepsilon_{r}-1}\left(\frac{L}{W}\right)^{2}$, a simple formulation is elaborated by the work carried out in [20] for the calculation of the length and the width of the notch in order to have a good adaptation.

(c) at this stage we chose to use the slot technology in the patch we made two asymmetrical U-shaped slot in such a way as to have the beginning of double resection, and to adjust on the two rectangular small slot to get a 
desirable frequencies (transmission and reception), we used the experience that was in this work of M.pachiyaannan [9].

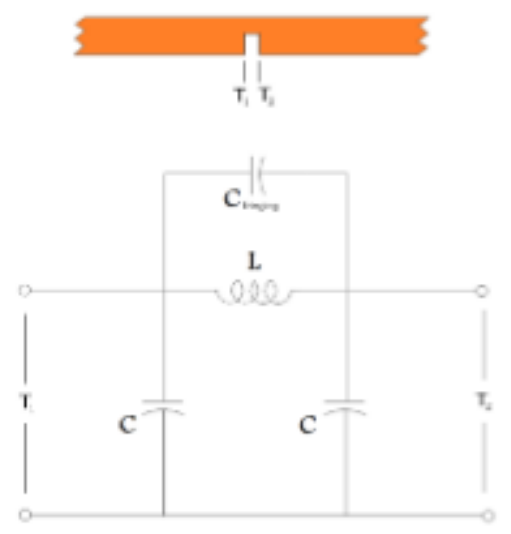

Fig.5. Rectangular small slot

Most of the studies of the U-slot patch antenna were concerned with its broadband capabilities. However, recent studies have shown that it can be also used for dual- or multiband designs. There are two approaches, depending on whether the frequency ratios are larger than or less than about 1.5. The two cases will be referred to as large frequency ratio and small frequency ratio, respectively [8]. Simple approach to designing dual-band patch antenna with frequency ratios of less than about 1.5 has been introduced in Lee and al. (2008, 2011). The method starts with a broadband antenna. When we use U-slot patch antenna in a special size, the bandwidth starts to widen towards the U-slot length frequency.

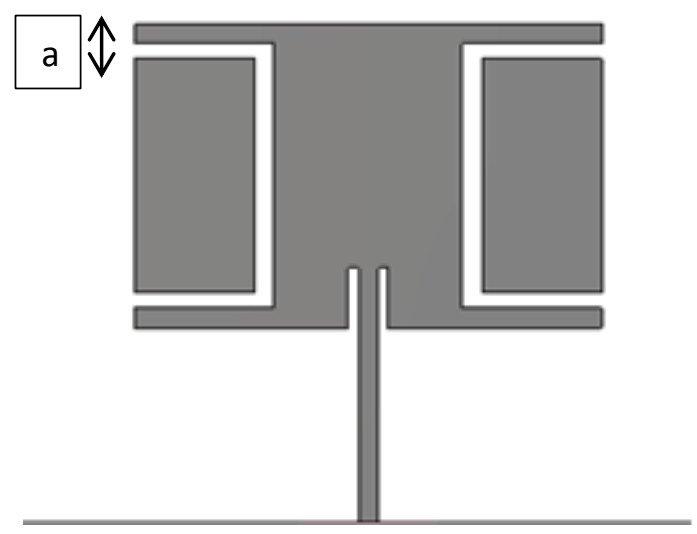

Fig.6 Two U-slot patch antenna

We have chosen to adjust parameter " $a$ " " that presents the width of the arm of U-slot :

Table 2. Table the change of frequency depending on a.

\begin{tabular}{|c|c|c|c|c|c|c|}
\hline $\mathrm{a}(\mathrm{mm})$ & 0.3 & 0.8 & 1.2 & 1.8 & 2 & $\mathrm{Lu} / 2$ \\
\hline$f_{r}$ & $34-29 \mathrm{GHz}$ & $32-27 \mathrm{GHZ}$ & $31-26 \mathrm{GHZ}$ & $29.5-27 \mathrm{GHZ}$ & $28-26 \mathrm{GHZ}$ & $28-23 \mathrm{GHZ}$ \\
\hline
\end{tabular}




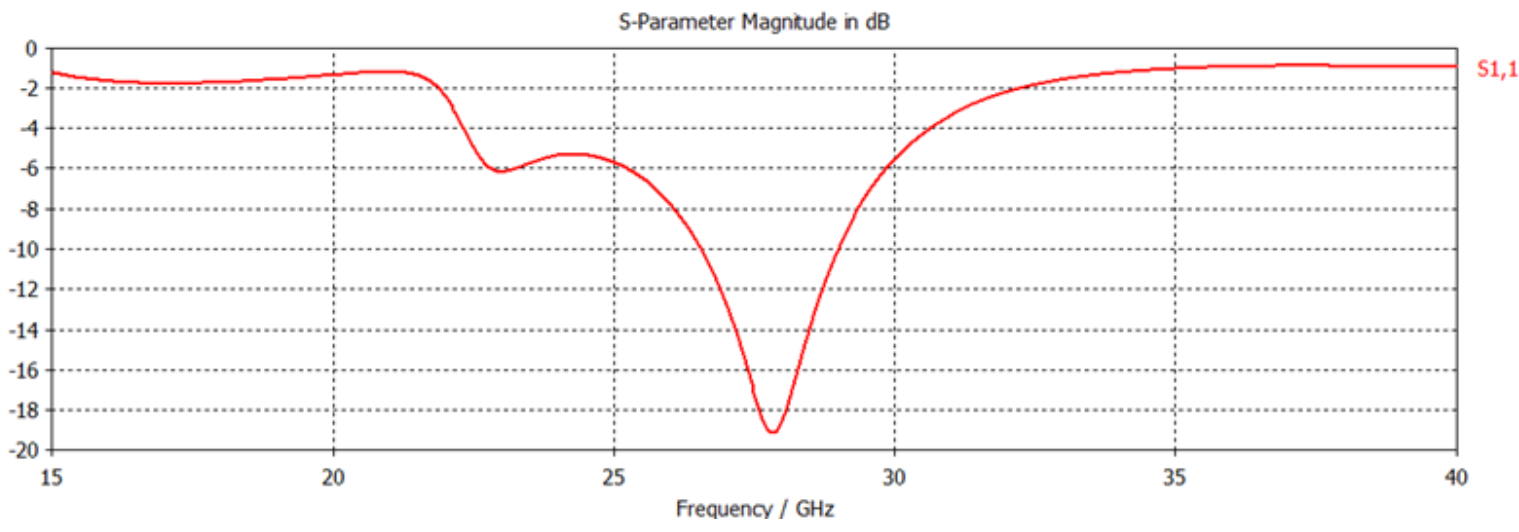

Fig.7. S-parameter S11 Patch antenna when $a$ equal $\boldsymbol{l}_{\boldsymbol{u}} / \mathbf{2}$

(d) in this step an L-shaped slot used at the feed line that allows a current flow of the surface capable of adapting two resonance frequencies that was already produced by the two U-slot. (e) in the final step the antenna load by $\mathrm{H}$ slot in order to obtain a voltage standing wave ratio less than 2 (until 0.9). Figure .4. shows the development of the reflection's coefficient and the creation of multiband with a wide band according to the antenna design advancement a function of different stages used (a,b,c,d and e).

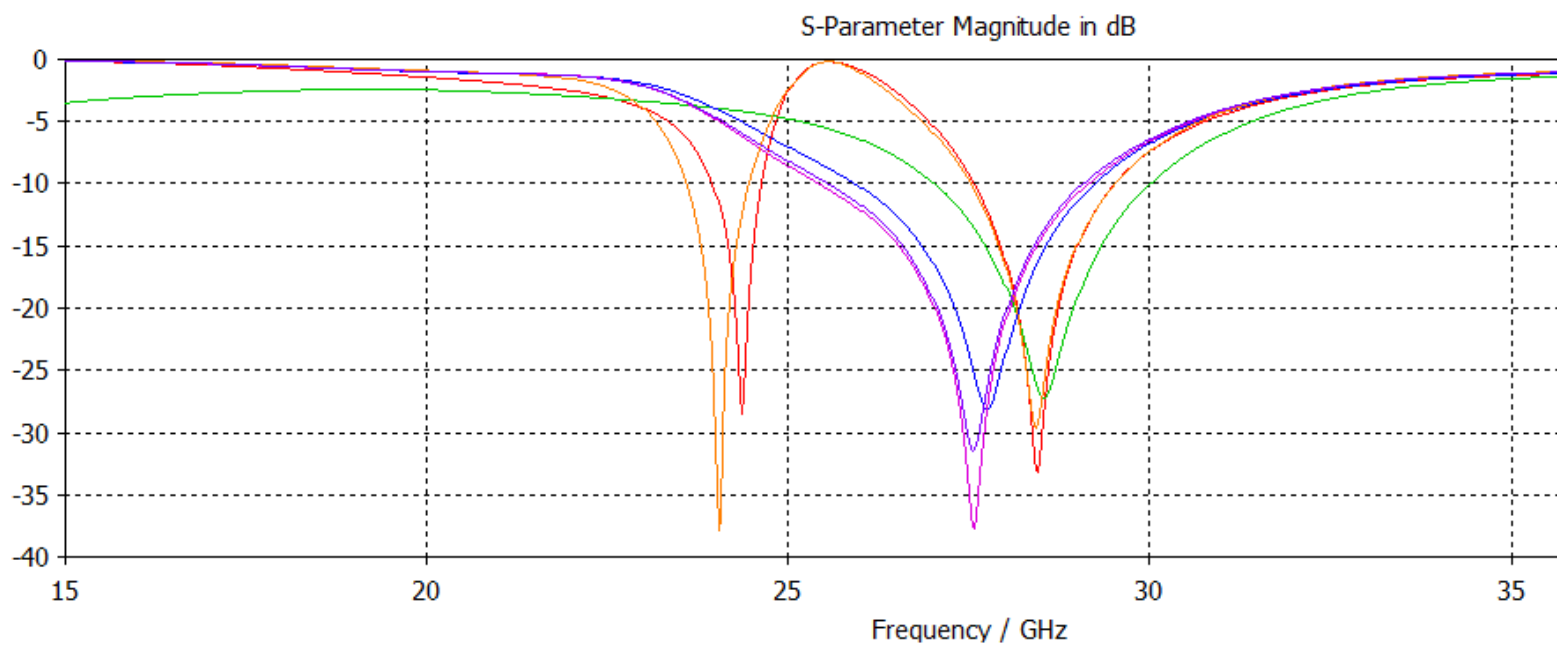

Fig.8. Simulated Return loss of different setups

Figure 5,6. Shows the return loss and VSWR characteristics of the proposed antenna which satisfying Kaband UWB operating frequency. The antenna exhibits dual resonance at $23.8 \mathrm{GHz}$ and $28.36 \mathrm{GHz}$ and its having a return loss of $-28.16 \mathrm{~dB}$ and $-40.23 \mathrm{~dB}$. This bandwidth is characterized by an ultra-wide band and voltage standing wave ratio $<2$.

- At $10 \mathrm{~dB}$ return loss display a bandwidth at $1 \mathrm{GHz}$ in the vicinity of $23.3-24.3 \mathrm{GHz}$ at $23.8 \mathrm{GHz}$, thus VSWR 1.09 .

- At $10 \mathrm{~dB}$ return loss display a bandwidth at $2 \mathrm{GHz}$ in the vicinity of $27.4-29.4 \mathrm{GHz}$ at $28.36 \mathrm{GHz}$, thus VSWR is 1.006 . 


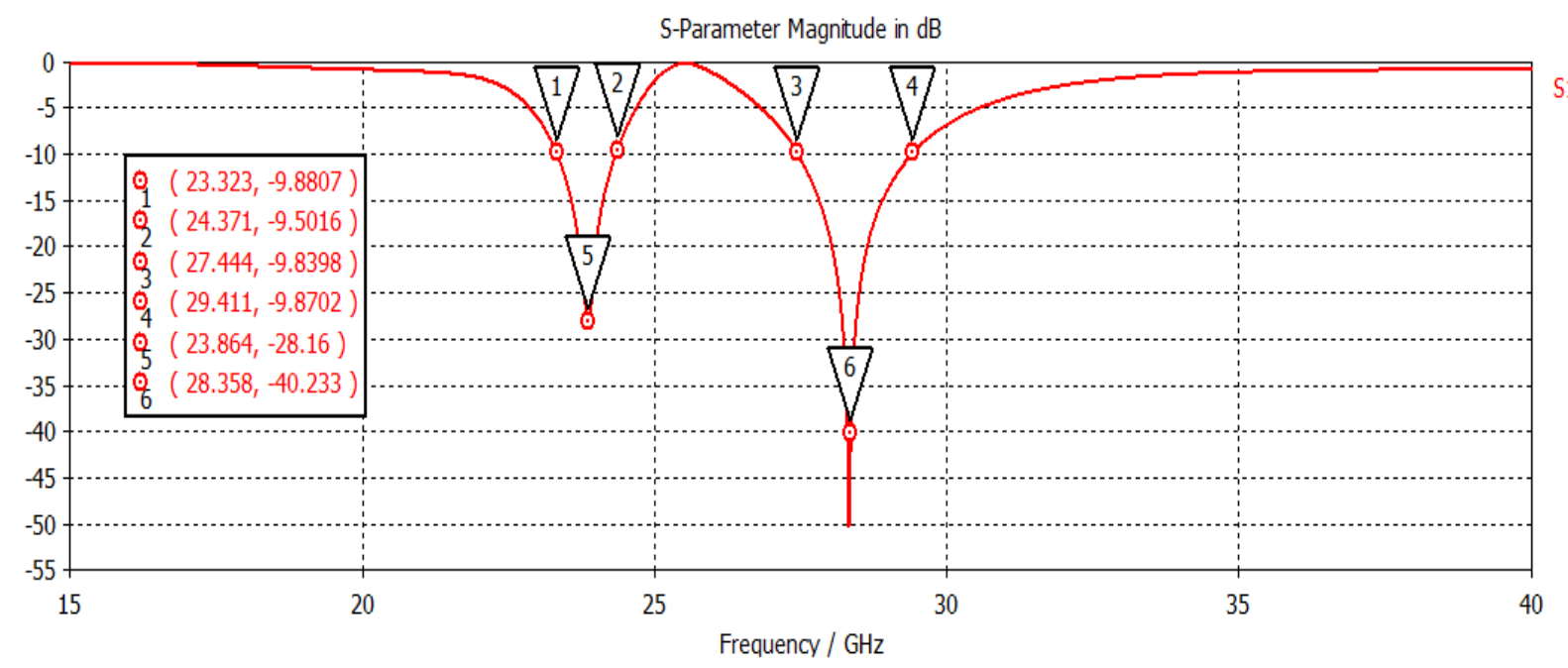

Fig.9. Simulated Return Loss of proposed antenna

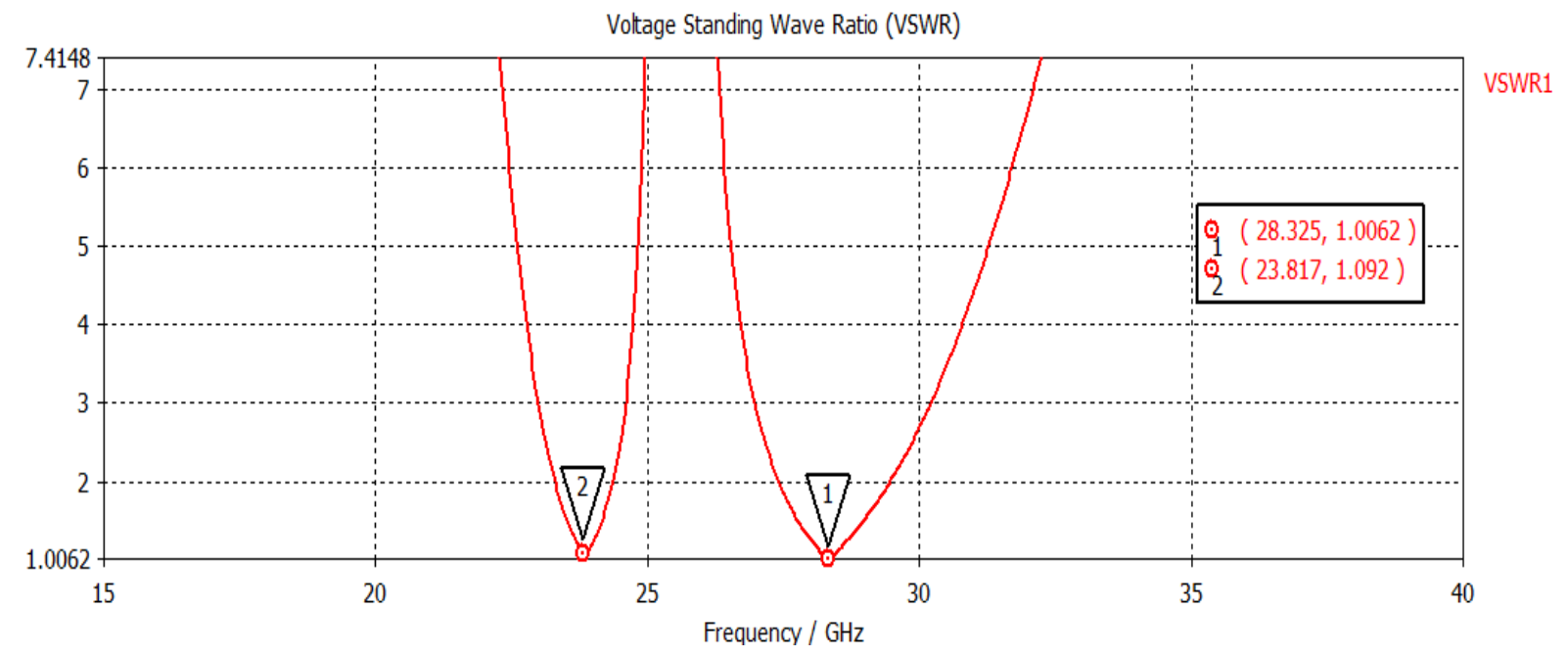

Fig.10. Simulated VSWR of proposed antenna

The simulated radiation efficiency of proposed antenna is shown in Figure 8. The frequency Vs radiation curve observe that the radiation efficency is greater than $92 \%$ in the both frequancy [23.8-28.3] Ghz.

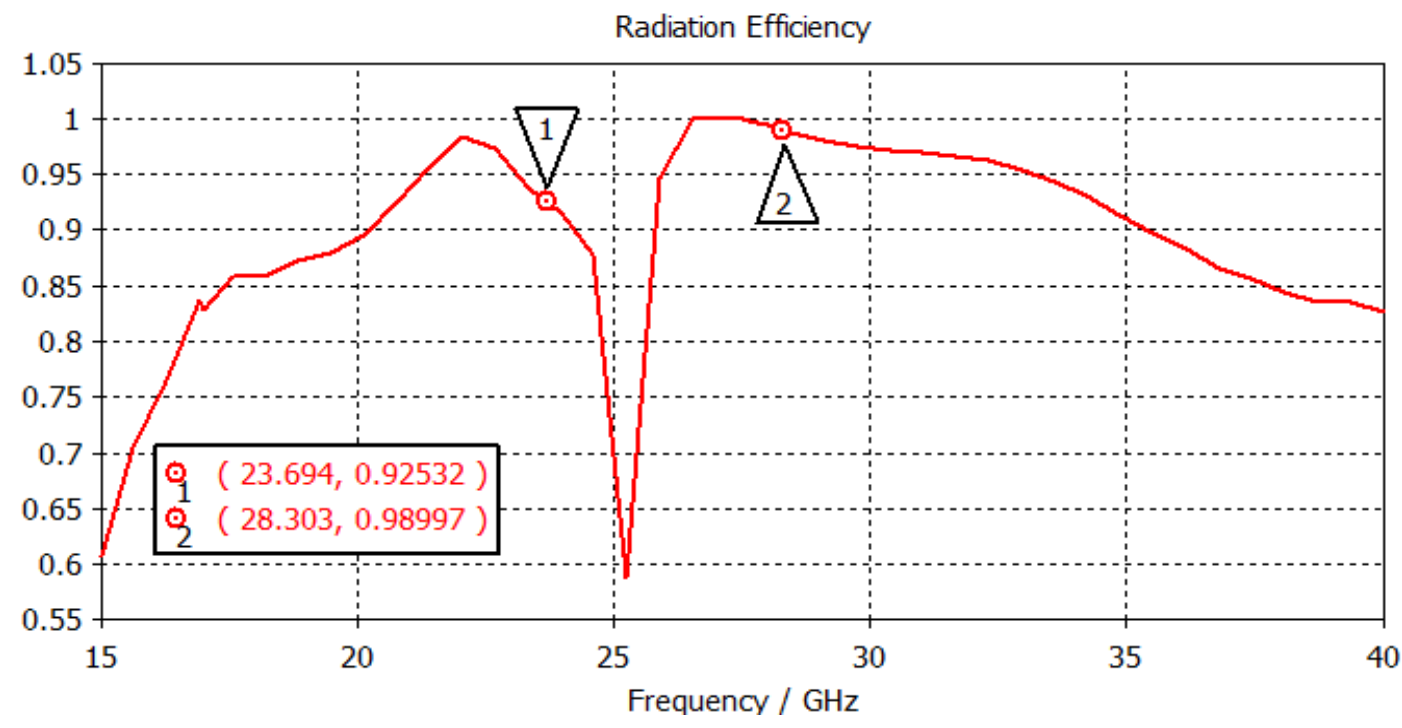

Rad. Effic. [1]

Fig.11. Simulated radiation efficiency proposed antenna 
The peak gain of antenna defines that the ratio of the intensity in a given direction to the radiation intensity that would be obtained if the power accepted by the antenna were radiated isotropically. Figure 9 shows the antenna peak gain in $2 \mathrm{D}$ patterns. The gain of proposed antenna obtained peak gain at $3.02 \mathrm{~dB}$ and $4.3 \mathrm{~dB}$ for the corresponding frequency of $23.7 \mathrm{GHz}$ and $28.8 \mathrm{GHz}$ which is moderate gain for this operating band this gain is highly suitable for radar applications.

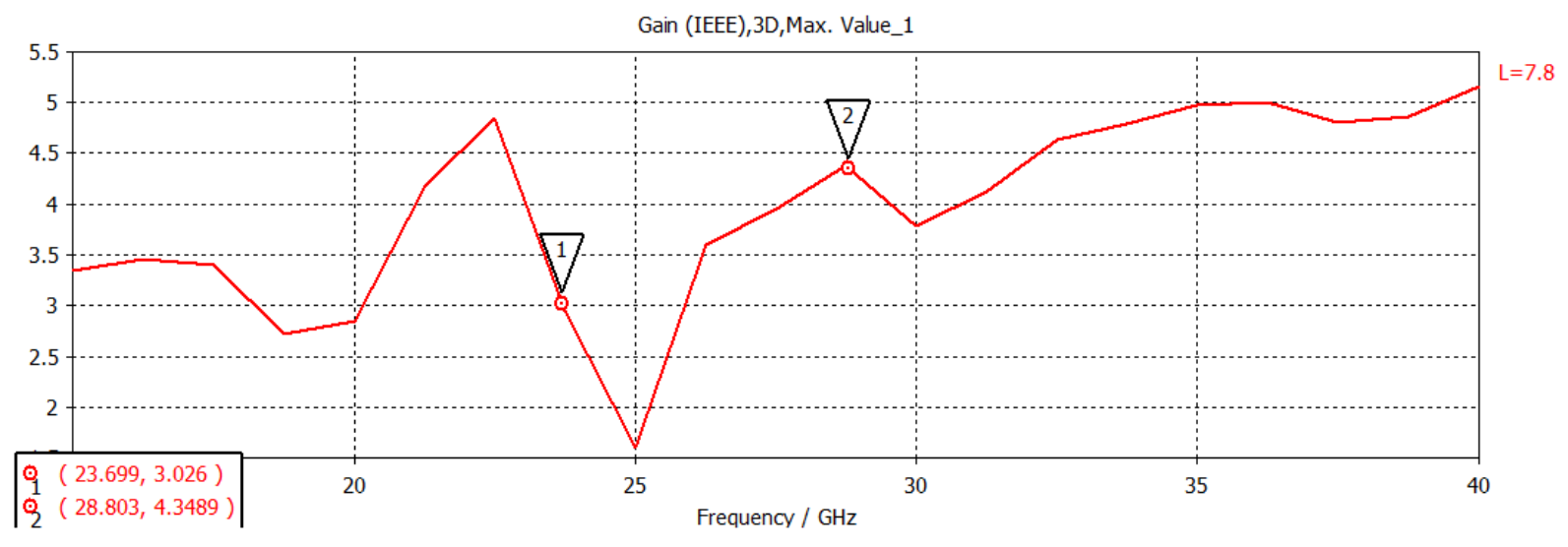

Fig.12. Simulated peak gain of proposed antenna

In literature there are more studies and researches carried out to develop the performances of the antennas in order to obtain the antenna answers as the given exigencies. In this work we compare the results obtained with very interesting work that deals with the same demands. Compact size K-band UWB antenna for surface movement radar: Design and analysis[10], Dual-band UWB antenna for Radar applications: Design and Analysis [21]. The following table shows the value of each work:

Table 3. The comparison table between the proposed antenna and the two examples.

\begin{tabular}{|c|c|c|c|c|c|c|}
\hline & \multicolumn{2}{|c|}{ Proposed antenna } & \multicolumn{2}{|c|}{ Example [10] } & \multicolumn{2}{|c|}{ Example [21] } \\
\hline Frequency & $23.3-24.3 \mathrm{GHz}$ & $27.4-29.4 \mathrm{GHz}$ & $19.8-20.7 \mathrm{GHz}$ & $25.4-27.2 \mathrm{GHz}$ & $5.7-16.5 \mathrm{GHz}$ & 22.9-23.7GHz \\
\hline Bandwidth & $1 \mathrm{GHZ}$ & $2 \mathrm{GHZ}$ & $0.9 \mathrm{GHZ}$ & $1.7 \mathrm{GHZ}$ & $800 \mathrm{MHZ}$ & $500 \mathrm{MHZ}$ \\
\hline Gain & $3 \mathrm{~dB}$ & $4.4 \mathrm{~dB}$ & $2.6 \mathrm{~dB}$ & $3.9 \mathrm{~dB}$ & $4.6 \mathrm{~dB}$ & $3.8 \mathrm{~dB}$ \\
\hline S11 & $-25.16 \mathrm{~dB}$ & $-40.23 \mathrm{~dB}$ & $-20.2 \mathrm{~dB}$ & $-26.2 \mathrm{~dB}$ & $-24 \mathrm{~dB}$ & $-23.6 \mathrm{~dB}$ \\
\hline Efficiency & $93.1 \%$ & $98.9 \%$ & $94.6 \%$ & $97.2 \%$ & $95.1 \%$ & $93.2 \%$ \\
\hline VSWR & 1.07 & 1.02 & 0.6 & 1.2 & 1.14 & 1.24 \\
\hline
\end{tabular}

according to the comparison table, the proposed structure presents very important advantages to the adaptation, gain and bandwidth parameter which meets the need for a movement surface radar antenna [2] .the proposed antenna frequency margin to reach a very interesting range in the field of aviation and satellite communication. 


\section{CONCLUSIONS}

In this document, we explained the study that we have conducted to obtain an elementary antenna for the movement surface radar which has important characteristics for a radar antenna in the ka-band, this result is presented as the obtain of a $23 \mathrm{Ghz}$ and a $28 \mathrm{Ghz}$, multi band frequencies with UWB of 1 and $2 \mathrm{Ghz}$. the two frequencies present the emission and the reception of the antenna. The proposed antenna presents interesting results in terms of gain and bandwidth in the Ka- band, the next studies will be dedicated to put this element in an antenna network in order to have a high gain and increase the directivity to finally have a radar antenna respecting the requirements mentioned in this paper (gain, bandwidth, radiation pattern, polarization). 


\section{References}

[1] International Civil Aviation Organization: Advanced Surface Movement Guidance and Control Systems (A-SMGCS) Manual. Doc 9830 (2017)

[2] EUROCONTROL : Specification for Advanced-Surface Movement Guidance and Control System (A-SMGCS) Services. (No.171) - Version 1.0. 01 March (2018)

[3] Xinping Chen ; Zhonghui Gao ; Yunfeng Chai : The development of air traffic control surveillance radars in China" IEEE Radar Conference. pp. 1776 - 1784 (2017)

[4] P.N. Melezhik ; V.B. Razskazovskiy ; N.G. Reznichenko ; V.A. Zuykov ; A.V. Varavin ; Yu.B. Sidorenko ; S.V. Provalov; F.J. Yanovsky : High-efficiency millimeter wave coherent radar for airport surface movement monitoring and control. 8th European Radar Conference. pp. 361 - 364 (2011)

[5] Université de Blida, Faculté des sciences de l’ingénieur. Radar course. Vol. 2, pp. 30- 40 (2010)

[6] Md. Naimur Rahman ; Mohammad Tariqul Islam ; Norbahiah Misran ; Md. Samsuzzaman: A tuning fork-shaped microstrip patch antenna for X-band satellite and radar applications. 6th International Conference on Electrical Engineering and Informatics. Pp. 1 - 2 (2017)

[7] N. Prema, : Design of multiband microstrip patch antenna for C and X band, Optik-International Journal for Light and Electron Optics, vol. 127, pp. 8812-8818, (2016)

[8] F. Oktafiani ; Y. P. Saputera ; Y. Wahyu : Microstrip patch array antenna with horizontal polarization for ISRA RADAR. International Conference on Radar, Antenna, Microwave, Electronics, and Telecommunications. pp. 169 - 173 (2017)

[9] Victor J. Marrero-Fontanez ; Rafael A. Rodriguez-Solis : Dual polarized microstrip antenna array for X-band radar applications. IEEE Antennas and Propagation Society International Symposium. pp . 2144 - 2147 (2007)

[10] M. Pachiyaanan ; G. K. D. Prasanna Venkatesan : Compact size K-band UWB antenna for surface movement radar: Design and analysis. International Conference on Applied and Theoretical Computing and Communication Technology. pp. $693-696(2015)$

[11] Simon Mener ; Raphael Gillard ; Langis Roy : A Dual-Band Dual-Circular-Polarization Antenna for Ka-Band Satellite Communications. IEEE Antennas and Wireless Propagation Letters. Volume: 16, pp. 274 - 277 (2017)

[12] Ansari, J.A.., Singh, P., Dubey, S.K., Khan, R.U., and Vishvakarma, B.R. : H-Shaped Stacked Patch Antenna For Dual Band Operation, Progress In Electromagnetics Research B, Vol. 5, 291-302 (2008)

[13] Jhamb, K., Li, L., and Rambabu, K.: Frequency adjustable microstrip annular ring patch antenna with multi-band characteristics", IET Microw. Antennas Propagation. Vol. 5, Iss. 12, pp. 1471-1478 (2011)

[14] Chen, S.B., Jiao, Y.C., Wang, W., and Zhang, F.S : Modified T-shaped planar monopole antennas for multiband operation. IEEE Transactions on Microwave Theory and Techniques, Vol. 54, no. 8, pp. 3267-3270, 2006.

[15] Kai-Fong Lee., and Kin-Fai Tong. : Microstrip Patch antennas-Basic characteristics and some recent advances, Proceedings of IEEE, Vol. 100, No.7,July (2012)

[16] Motinl,M.A.,Imran Hasan,Md., and Asaduz-Zaman.Md : Design and Optimisation of a Low Cost Multi Band Microstrip Patch Antenna for KBand, Ku-Band and X-Band Applications. (2012)

[14] Kin-Lu Wong : Compact and Broadband Microstrip Antennas John Wiley \& Sons, Inc, Third Edition,pp.4579,.Publication (2002)

[18] I. J. Bahl and P. Bhartia : Microstrip Antennas. Artech House, Boston, Mass, USA, 2nd edition, (1980)

[19] A. F. Alsager, "Microstrip Antennas ”Design and analysis of Microstrip Patch Antenna Arrays

[20] M. Ramesh and YIP KB Design Formula for Inset Fed Microstrip patch antenna. Journal of Microwaves and optoelectronics, Vol. 3, N. 3, December 2003.

[21] M. Pachiyaannan ; G. K. D. Prasanna Venkatesan : Dual-Band UWB Antenna for Radar Applications: Design and Analysis, 8th International Conference on Computational Intelligence and Communication Networks (CICN). Page s: 196 199 (2016) 